\title{
SOLUBILIDADE E DISPONIBILIDADE DOS MICRONUTRIENTES EM FERTILIZANTES ${ }^{(\mathbf{1})}$
}

\author{
F. VALE ${ }^{(2)} \& J$. C. ALCARDE ${ }^{(3)}$
}

\begin{abstract}
RESUMO
A legislação brasileira exige que os micronutrientes nos fertilizantes sejam garantidos pelo teor total presente. Isto abre um precedente para a utilização de produtos não considerados como fontes de micronutrientes na fabricação dos fertilizantes. Todavia, a eficiência agronômica desses produtos é ainda duvidosa. Objetivou-se realizar um trabalho para caracterizar a solubilidade e a disponi bilidade dos mi cronutrientes em trinta fertilizantes comerciais, por meio do uso de cinco extratores químicos: a água e soluções de ácido cítrico a $2 \%$, de citrato neutro de amônio na diluição $1+9$, de DTPA $0,005 \mathrm{~mol} \mathrm{~L}^{-1}$ e de EDTA $0,005 \mathrm{~mol}^{\mathrm{L}}-1$. Os resultados mostraram a baixa solubilidade dos micronutrientes metálicos (cobre, ferro, manganês e zinco) dos fertilizantes ti po "fritas". 0 ácido cítrico a $2 \%$ mostrou-se promi ssor na caracterização da disponibi lidade de cobre, manganês e zinco para as plantas. Para o ferro não houve uma definição entre os extratores estudados. $O$ boro teve boa solubilidade, tanto nos fertilizantes solúveis, como nos insolúveis em água, e a garantia pelo teor total mostrou-se bom indicativo da disponi bilidade do elemento. Para o moli bdênio a solubilidade foi maior para os fertilizantes com baixo teor do elemento. A garantia dos micronutrientes catiônicos pelo teor total, conforme exige a legislação, não indicou a sua real disponibilidade nos fertilizantes comerciais, mostrando a necessidade de uma definição de extratores para esse fim.
\end{abstract}

Termos de indexação: legislação, extratores.

(1) Parte da Dissertação de Mestrado do primeiro autor, apresentada à ESALQ/USP, em 1997. Com auxílio financeiro da FAPESP . Recebido para publicação em dezembro de 1997 e aprovado em dezembro de 1998.

(2) Engenheiro-Agrônomo, aluno de pós-graduação da ESALQ/USP. Caixa Postal 9, CEP 13418-900 Piracicaba (SP). E-mail fvale@carpa.ciagri.usp.br. Bolsista da FAPESP

(3) Professor Titular do Departamento de Química, ESALQ/USP. 


\title{
SUMMARY: MICRONUTRIENT SOLUBILITY AND AVAILABILITY IN FERTILIZERS
}

\begin{abstract}
The Brazilian fertilizer legislation requires that the presence of micronutrients be guaranteed by their total amount. This makes possi bl eto use different products as sourceof micronutrients for fertilizers, but their agronomic efficiency is still doubtful. Thepurpose of this work was to characterize the micronutrient solubility and availability of thirty commercial fertilizers through five extractors: water, $2 \%$ citric acid, neutral ammonium citrate $(1+9), 0.005 \mathrm{~mol} \mathrm{~L}^{-1}$ DTPA and $0.005 \mathrm{~mol} \mathrm{~L}^{-1}$ EDTA solutions. Theresults showed low solubility of $\mathrm{Cu}, \mathrm{Fe}, \mathrm{Mn}$ and $\mathrm{Zn}$ in "fritted" fertilizers. The $\%$ citric acid has shown to be a good extractor to identify $\mathrm{Cu}, \mathrm{Mn}$ and $\mathrm{Zn}$ availability for plants. The B solubility was suitablein all fertilizers and its total amount showed to bea good indication of B availability. The Mo solubility presented high values for fertilizers with low amount of total Mo, but lower values for fertilizers with high amount of total Mo. The guarantee of total amount of micronutrients in fertilizers did not indicate their availability: it is necessary to establish an extractor in order to quantify micronutrient availability.
\end{abstract}

Index terms: legislation, extractors.

\section{NTRODUÇÃO}

A legislação brasileira define algumas características para os fertilizantes usados como fontes demicronutrientes (Brasil, 1982). Esta mesma legislação, porém, abre um precedentequepodeestar sendo usado por fabricantes inescrupulosos: a garantia eos métodos oficiais deanál ise contemplam o teor total dos micronutrientes (Brasil, 1983). Isto dá oportunidade de comercializar diversos subprodutos industriais que contenham micronutrientes, com teores totais mínimos exigidos, mas nas formas químicas diferentes com que se rotulam e previstas na legislação. Um exemplo dessa fraudeé a comercialização de zinco metálico sob o rótulo de óxido de zinco.

Essas formas químicas não contempladas na legislação como fonte de micronutrientes, como o zinco metálico, silicato de zinco e sulfeto de zinco, são de eficiência agronômica ainda duvidosa e, além disso, podem conter teores el evados de contami nantes os quais, com o passar dotempo, tornam-se grandes poluentes dos solos, afetando a produtividade e a qualidade dos produtos agrícolas.

Nos métodos de determinação de mi cronutrientes da AOAC - American Official Analytical Chemistry (Kane, 1995), são apresentados procedimentos para determinação de $\mathrm{Fe}$ e $\mathrm{Zn}$ solúveis em água e em EDTA $2,5 \%$, e de $M n$ solúvel em água e em ácido, neste caso discriminando $\mathrm{Mn}^{2+}$ e $\mathrm{Mn}^{4+}$. A metodologia japonesa (J apão, 1982), por outrolado, apresenta procedimentos para determinação de teores solúveis em água de $\mathrm{Mo}, \mathrm{Cu}, \mathrm{Fe}, \mathrm{Hg}, \mathrm{Mn}, \mathrm{Cr}$, $\mathrm{Zn}, \mathrm{Cd}$ e $\mathrm{Pb}$. Inclui ainda método para extração de Mn em ácido cítrico.
A água é considerada como um extrator universal, cuja composição do extratoé uma excel ente indicação da presença de elementos altamente solúveis e prontamente disponíveis às plantas, seja em solos ou fertilizantes.

Alcarde \& Ponchio (1979) esclareceram a ação solubilizante dos extratores usados na determinação do fósforo solúvel dos fertilizantes. O citrato neutro de amônio (CNA) é uma solução tamponada relativamente concentrada, neutra $(\mathrm{pH} 7,0)$, enquanto a solução de ácido cítrico (AC) é relativamente diluída, mas de acidez el evada (pH 2,30). Demonstraram os autores, com base nas constantes de estabilidade do ânion citrato, que o CNA, no pH neutro, e o AC, em condições de acidez, tendem a formar complexos com cátions presentes e passíveis de serem disponíveis, entre eles o Ca, $\mathrm{Cu}, \mathrm{Fe}, \mathrm{Mg}, \mathrm{Mn}, \mathrm{Na}$ eZn. Fica clara a capacidade dos dois extratores em solubilizar os micronutrientes metálicos. Em contrapartida, são liberados para a sol ução os ânions acompanhantes, como os fosfatos, sulfatos, molibdatos e boratos. Os autores citaram, também, que as características físico-químicas dos fertilizantes, como estrutura cristalina, grau de pureza e porosidade, são de grande importância na solubilização.

Os agentes quelantes mostraram-se também promissores para avaliar a disponibilidade de micronutrientes catiônicos no solo, pois podem combinar com os metais livres em solução, formando complexos iôni cos solúveis, reduzindo a atividade do metal no estado de máxima oxidação. Em resposta, os metais são solubilizados, desligando-se da fase sól ida para reabastecer os metais livres na solução, até atingir o equilíbrio. A quantidade de metais 
acumulados na sol ução durante a extração depende tanto da atividade do íon metálico, como da habilidade do solo em repor esses íons (Lindsay \& Norvell, 1978). Esses mesmos autores utilizaram o ácido dietilenopentacético (DTPA) como extrator de $\mathrm{Cu}, \mathrm{Fe}, \mathrm{Mn}$ e $\mathrm{Zn}$ dos solos. Escol heram a solução de DTPA a pH 7,30 por ser a que apresentava a mais favorável combinação de constantes de estabilidade para compl exações simultâneas dos micronutrientes metálicos, além de mostrar maior habilidade para complexar Cu, Fe, Mn eZn, em competição como Ca eMg.

Outroagentequelantebastantecitadoe utilizado éoácido etilenodiami notetracético(EDTA). Ringbom (1963) relatou que os valores de $\mathrm{pH}$ em que as constantes de estabilidade do EDTA complexar $\mathrm{Cu}$, $\mathrm{Fe}, \mathrm{Mn}$ e $\mathrm{Zn}$ estão entre 9 e 10.

Em recente pesquisa, Alcarde \& Rodella (1993) objetivaram estabel ecer um procedimento analítico, viável de utilização em rotina, que permitisse reconhecer se um material contendo zinco pode ou não ser considerado fertilizante simples. Os resultados mostraram que a fervura da amostra com a solução de citrato de amônio na diluição $(1+9)$ foi a que melhor caracterizou os fertilizantes simples que continham zinco insolúvel em água.

Em estudos de disponibilidade de nutrientes em fertilizantes são importantes as correlações entre os teores adicionados pel o fertilizante e os absorvidos por plantas. O método de Neubauer \& Schneider, citado por Catani \& Bergamin Filho (1961), podeser utilizado para a avaliação da quantidade denutrientes disponíveis no solo e baseia-se no conceito de que grande número de plantas cultivadas num pequeno volume de terra haverão de, em pouco tempo, exaurir os el ementos disponíveis da amostra de terra.

Dada a carência de uma análise que possibilite caracterizar devidamente os produtos que contenham micronutrientes e reconhecidos como fertilizantes simples, desenvolveu-se o presente trabalho, com vistas em identificar a solubilidade e a disponibilidade dos micronutrientes em fertilizantes comerciais, por meio de extratores químicos, viáveis de utilização de rotina.

\section{MATE RIAL E MÉTODOS}

O estudo foi desenvolvido no Departamento de Química da Escola Superior deAgricultura “Luiz de Queiróz" - ESALQ, da Universidade de São Paulo. Foram utilizadas 30 amostras de fertilizantes comerciais diferentes, sendo sel ecionados produtos considerados de solubilidade lenta, como as fritas e boratos, e produtos mais solúveis, como os sais e quel atos, para aplicação fol iar, em que, teoricamente todo o mi cronutriente está prontamente disponível. As garantias desses fertilizantes encontram-se listadas no quadro 1. As amostras foram col etadas, segundo método descrito em Brasil (1982), encaminhadas ao laboratório para serem preparadas, visando à homogeneização das amostras, sendo quarteadas em quarteador tipo "J ones" atése atingir, aproximadamente, 100 gramas de fertilizante por amostra. A seguir, as amostras foram moídas manualmente, em gral de porcelana, até que passassem por completo em peneira com abertura de malha de 0,84 mm (ABNT no 20). I mportante observação ocorrida nesta fase foi a presença de certa quantidade de impurezas metálicas de diâmetro superior a $0,84 \mathrm{~mm}$ que ficavam retidas na peneira, como fios de cobre, pontas de aço, etc. Visualmente, observaram-se muitas impurezas metálicas com diâmetro de partículas menores que o da malha da peneira utilizada, as quais passaram para a porção de fertilizantea ser anal isada, provavel menteinsolúveis no solo, mas com seu teor de micronutrien-tes contemplado numa análise pel o teor total.

Todos os produtos foram analisados quanto ao teor total de micronutrientes, oteor solúvel emágua, e solúvel em soluções de áci do cítrico a $2 \%$, de citrato neutro deamônio $(1+9)$, deácido di etilenopentacético (DTPA) 0,005 mol L-1 e de ácido etilenodiaminotetracético (EDTA) 0,005 mol L-1. Com exceção do teor total, outros métodos são apresentados neste trabalho. A escol ha desses extratores baseou-se no fato de a água ser considerada o extrator universal, o ácido cítrico e o citrato neutro de amônio, por já serem utilizados na rotina para determinação de fósforo solúvel em fertilizantes, eDTPA eEDTA, por serem utilizados na análise de solos para avaliar micronutrientes disponíveis.

\section{Extrações}

\section{Teor total de micronutrientes - (Brasil, 1983)}

Teor de micronutrientes solúveis em água Foram transferidos 2,5000 g da amostra para papel de filtro faixa branca adaptado em funil e colocado sobre balão de $250 \mathrm{~mL}$. O material foi lavado com porções sucessi vas de água destilada, tendo o cuidado de promover a suspensão da amostra. Procedeu-se à extração até quase compl etar $250 \mathrm{~mL}$. Nos filtrados que apresentaram turbi dez, foram adicionados $2 \mathrm{~mL}$ de solução de $\mathrm{HNO}_{3}(1+1)$. Completou-se o volume. Foi preparada uma prova em branco.

Teor de micronutrientes solúveis em solução de ácido cítrico a $\mathbf{2 \%}(\mathrm{AC})$, em solução neutra de citrato de amônio (1 +9) - (CNA), em solução de DTPA 0,005 mol L-1 e em solução de EDTA 0,005 mol L-1 - Para todas estas extrações, o método utilizado foi o mesmo, somente modificandose o extrator.

Transferiram-se $1,0000 \mathrm{~g}$ da amostra para erlenmeyer de $250 \mathrm{~mL}$, adicionaram-se $100 \mathrm{~mL}$ do extrator etampou-secom rolha deborracha. Colocou-se o material em agitador tipo Wagner e agitou-se por uma hora, a 30-40 rpm. Transferiu-se o conteúdo do 
Quadro 1. Garantia de micronutrientes e forma física dos fertilizantes utilizados

\begin{tabular}{|c|c|c|c|c|c|c|c|c|c|c|}
\hline No & Identificação & Empresa & Tipo & B & $\mathrm{Cu}$ & $\mathbf{F e}$ & Mn & Mo & Zn & Forma \\
\hline & & & & \multicolumn{6}{|c|}{$-\%$} & \\
\hline 1 & FTE BR-12 & Nutriplant & Frita & 1,8 & 0,8 & 3,0 & 2,0 & 0,1 & 9,0 & Granulado \\
\hline 2 & FTE Sementes & Nutriplant & Frita & 2,5 & - & - & 2,0 & 6,0 & 25,0 & Pó \\
\hline 3 & FTE J CO 2M & Nutriplant & Frita & 2,0 & 5,0 & 5,0 & 8,0 & - & 5,0 & Pó \\
\hline 4 & FTE Centro Oeste & Nutriplant & Frita & 2,0 & 2,0 & - & 10,0 & - & 15,0 & Granulado \\
\hline 5 & Nutricitro 224 & Nutriplant & Frita & 2,0 & - & - & 4,0 & - & 20,0 & Pó \\
\hline 6 & Borogran - 10 & Nutriplant & Frita & 10,0 & - & - & - & - & - & Granulado \\
\hline 7 & Hidrozinc Frit 20 & Nutriplant & Frita & - & - & - & - & - & 20,0 & Granulado \\
\hline 8 & FTE Cerrrado S & Nutriplant & Frita & 0,5 & 1,06 & - & 6,0 & 0,01 & 13,0 & Pó \\
\hline 9 & Zincogran 20 & Nutriplant & Frita & - & - & - & - & - & 20,0 & Granulado \\
\hline 10 & FTE BR - 18 & Nutriplant & Frita & 3,6 & 1,6 & - & - & 0,2 & 18,0 & Granulado \\
\hline 11 & FTE BR - 8 & Nutriplant & Frita & 2,5 & 1,0 & 5,0 & 10,0 & 0,1 & 7,0 & Pó \\
\hline 12 & Zincoman & Nutriplant & Frita & - & 7,0 & - & 15,0 & - & 7,0 & Granulado \\
\hline 13 & Mib - 4 & Produquímica & Frita & 4,0 & - & - & - & - & 20,0 & Granulado \\
\hline 14 & Mib- 3 & Produquímica & Frita & 1,8 & 0,8 & 3,0 & 2,0 & 0,1 & 9,0 & Granulado \\
\hline 15 & Mib - 3 & Produquímica & Frita & 1,8 & 0,8 & 3,0 & 2,0 & 0,1 & 9,0 & Pó \\
\hline 16 & Mib- 16A & Produquímica & Frita & 2,5 & - & - & - & 1,3 & 25,0 & Granulado \\
\hline 17 & Mib - 28 & Produquímica & Frita & 2,0 & 2,0 & - & 10,0 & - & 15,0 & Granulado \\
\hline 18 & Agrimax-12 & Fertibrás & Frita & 1,8 & 0,8 & 3,0 & 2,0 & 0,1 & 9,0 & Granulado \\
\hline 19 & Gran-o-zinc 20 & Fertibrás & Frita & - & - & 1,0 & - & - & 20,0 & Granulado \\
\hline 20 & Gran-o-bor 10 & Fertibrás & Frita & 10,0 & - & - & - & - & - & Granulado \\
\hline 21 & Agrimax CO 150 & Fertibrás & Frita & 2,0 & 2,0 & - & 10,0 & - & 15,0 & Granulado \\
\hline 22 & HGB 12 & - & Frita & 2,0 & 2,0 & - & 10,0 & - & 15,0 & Pó \\
\hline 23 & Plantzinco F IV & Agroplanta & Frita & - & - & 1,0 & - & - & 40,0 & Farelado \\
\hline 24 & Plantzinco F II & Agroplanta & Frita & - & - & - & - & - & 20,0 & Farelado \\
\hline 25 & Ulexita & Produquímica & Borato & 12,0 & - & - & - & - & & Farelado \\
\hline 26 & Boro Importado & Argentina & Borato & 15,0 & - & - & - & - & - & Granulado \\
\hline 27 & Nitrex MS - 2 & Fertibrás & Sais & 1,5 & 1,0 & - & 8,0 & - & 10,0 & Pó \\
\hline 28 & Copas - 8 (café) & Copas & Sais & 3,0 & - & - & - & - & 8,0 & Pó \\
\hline 29 & Copas - 9 (citrus) & Copas & Sais & 2,0 & - & - & 9,0 & - & 11,0 & Pó \\
\hline 30 & Nutri Oxi-Zn "C" & Oxiquímica & Quelato & - & - & - & - & - & 21,5 & Líquido \\
\hline
\end{tabular}

erlenmeyer para balão de $250 \mathrm{~mL}$, completando-se o volume com água destilada, deixando em repouso para decantar. Usou-se o sobrenadante para as determinações. Foi preparada uma prova em branco.

As soluções de ácido cítrico a $2 \%$ e de citrato de amônio $(1+9)$ foram preparadas baseando-se em Brasil (1983).

A solução de DTPA foi a mesma proposta por Lindsay \& N orvell (1978) eque éutilizada hoje para a extração de mi cronutrientes metálicos disponíveis de solos, pelo princípio da quelação, com a única diferença que, no método adotado, a relação entre a massa da amostra e o extrator foi de 1:100, e não $1: 2$, conforme encontrado no referido trabal ho, pelo fato de os fertilizantes apresentarem uma concentração maior de micronutrientes que o solo.

A solução de EDTA foi preparada substituindo-se oDTPA por 1,86 g deEDTA e corrigindo-se o $\mathrm{pH}$ da solução para 9,3 por meio do uso de hidróxido de sódio concentrado.

As determi nações de $\mathrm{Cu}, \mathrm{Fe}$, Mn e Zn nos extratos foram feitas por espectrofotometria de absorção atômica, as de $B$, segundo método proposto pela AOAC (Kane, 1995), eas de Mo, segundoBrasil (1983), todas após convenientes diluições com água destilada.

Com base nos resultados das análises, foram realizadas correlações lineares entre o teor total de micronutrientes em cada fertilizante e os teores extraídos pelos diferentes extratores, visando identificar a coerência entre os teores presentes e a quantidadeextraída. Esse procedimentoéimportante, visto que correlações baixas podem indicar presenças de mi cronutrientes em forma não-disponível, assim como correlações altas podem indicar extração de formas não-solúveis. E ssas correlações foram feitas separadamente nos fertilizantes considerados solúveis e nos insolúveis, para seter uma tendência geral de como é a extração realizada por cada extrator perante o grupo de fertilizantes.

\section{Avaliação do aproveitamento dos micronutrientes pelas plantas}

Realizou-se uma avaliação do aproveitamento dos micronutrientes pelas plantas, utilizando-se o método de Neubauer \& Schneider (Catani \& 
Bergamin Filho, 1961). Em placas de Petri foram adicionadas camadas de sílica pré-lavadas com $\mathrm{HCl}$ $(1+2)$, para eliminar possíveis impurezas. O motivo da utilização da sílica foi que o sol o poderia fornecer micronutrientes para as plantas, o que dificultaria determinar se o micronutriente veio do solo ou do fertilizante. Cada placa recebeu uma dose de $1 \mathrm{mg}$ do fertilizante, de modo a fornecer a quantidade de cada el emento, conforme mostrado no quadro 2. Estas quantidades for am baseadas nos teores totais de micronutrientes, determinados neste trabalho.

Foram realizadas três repetições para cada fertilizante. Plantaram-se 40 sementes de arroz cv. IAC 201, em cada placa, cobrindo-se com uma fina camada de sílica. As placas foram irrigadas diariamente com $5 \mathrm{~mL}$ da solução nutritiva de Hogland \& Arnon (1950), isenta dos micronutrientes que estavam em cada fertilizante. Após 20-22 dias, as plantas foram col hidas por intei ro, lavadas, secas em estufa, pesadas, moídas e submetidas à determinação dos teores de micronutrientes, segundo Malavolta et al. (1989). Determinaram-se, em cada amostra, apenas os micronutrientes garantidos pelos fabricantes. O molibdênio não foi determinado, pois para sua análise são necessários $5,0 \mathrm{~g}$ de matéria seca, não obtidos no teste. Com os valores da matéria seca produzida e os teores absorvidos, calcularam-se as quantidades de cada micronutriente acumulado pelas plantas em cada tratamento. As correlações entre os teores de cada micronutriente extraído pel os diferentes extratores e os teores encontrados nas plantas foram usados como indicação da eficiência do extrator para cada micronutriente.

\section{RESULTADOS E DISCUSSÃO}

Zinco - Na figura 1a, encontram-se as correlações realizadas entre oteor total eos teores solubilizados pelos diferentes extratores, para os fertilizantes solúveis. Observa-sequetodos os extratores extraíram praticamente todo o zinco dos fertilizantes, podendose considerar que este se encontrava na forma solúvel. Tal comportamento só não foi observado na presença do EDTA. Essa alta extração pode ser caracterizada pel os el evados coeficientes angulares das retas apresentadas, pois, quanto mais próximo de 1,0 esse valor, maior a quantidade extraída em relação ao teor total. A alta solubilização pela água éindicativo da utilização de fontes solúveis na adição do zinco aos fertilizantes.

Quanto aos coeficientes de correl ação al tamente significativos apresentados pelos extratores água, AC, CNA e DTPA, pode-se dizer que a extração por eles foi proporcional ao aumento do teor total de zinco; para o EDTA, no entanto, o val or não foi significativo, e isto, associado à baixa solubilização de zinco, constitui provável indicativo de sua baixa eficiência na determinação de zinco solúvel, nesta concentração e no $\mathrm{pH}$ utilizado. Isto pode ser atribuído a preci pitação causada pelo val or do alto pH da solução, apesar de Ringbom (1963) demonstrar boa complexação dezinco peloEDTA na faixa de pH utilizado no trabalho.

Anal isando as comparações entre os teores totais de zinco e os teores extraídos pelos diferentes extratores, para as fritas (Figura 1b), nota-se, pel os baixos coeficientes lineares das retas, que todos os extratores solubilizaram menos zinco em relação ao teor total presente. Observam-se, ainda, três tendências diferenciadas de extração: o AC tendeu a extrair mais, seguido do CNA e DTPA, e com o EDTA e água extraindo menos. Quanto aos coeficientes de correlação, somente o AC e o CNA foram significativos, isto é, aumentavam a extração à medida que aumentava o teor de zinco nos fertilizantes. Isto pode indicar que o extrator extraiu também formas insolúveis presentes. Uma explicação que pode ser dada ao valor $r=0,91$ do
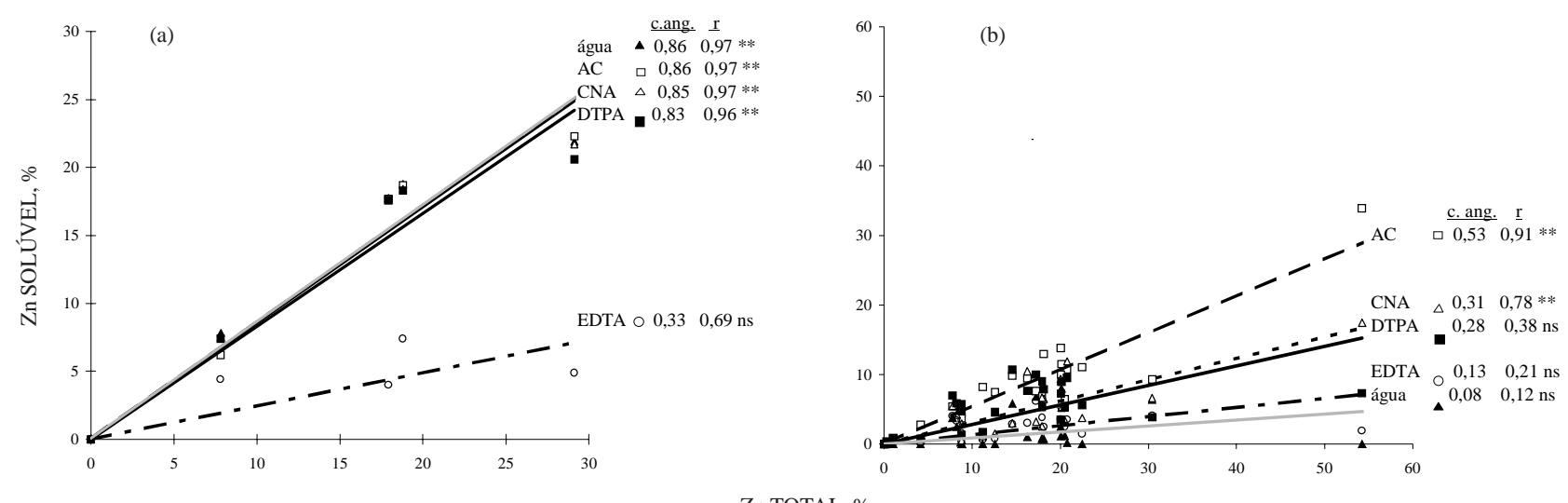

Figura 1. Solubilidade do zinco presente em fertilizantes comerciais solúveis (a) e insolúveis em água (b), nos diversos extratores utilizados, e respectivos coeficientes angulares das retas (c.ang.) e coeficientes de correlação ( $r$ ). ** e ns significativo a 1\% e não-significativo, respectivamente. 
extrator AC é que a acidez el evada apresentada por ele, com pH em torno de 2,3 (Alcarde \& Ponchio, 1979), podeestar solubilizando formas pouco solúveis dezinco. Da mesma forma, o coeficiente de correlação não-significativo apresentado pelo DTPA, por exemplo, pode ser devido aos diferentes materiais utilizados na fabricação dos fertilizantes, fazendo com que cada um tenha um teor diferente de zinco disponível.

Ferro - No estudo deste el emento, não se utilizou nenhum fertilizante com presença de ferro considerado solúvel, pois não foi encontrado no mercado nenhum produto com essa característica.

A baixa solubilização do ferro presente nas fritas por todos os extratores, em relação aos teor es totais, émostrada na figura 2. Constata-seque os extratores água, DTPA e EDTA não conseguiram solubilizar ferro. Ringbom (1963) e Lindsay \& Norvell (1978) demonstraram a capacidade de quelatação do ferro disponível em solução pelo DTPA e EDTA. A solubilidade igual a zero em água é indicativo da utilização de produtos com ferro insolúvel na produção dos fertilizantes. $\mathrm{O}$ extrator $\mathrm{AC}$ foi o que mais sol ubilizou ferro; sua acidez (Alcarde\& Ponchio, 1979) provavel mente favoreceu a liberação de ferro insolúvel à solução. A quantidade solubilizada, porém, foi muito baixa em relação ao teor total. O extrator CNA extraiu quantidade muito pequena de ferro. É interessante observar quea correlação entre o teor total presente nos fertilizantes e o extraído por esses dois últimos extratores foi significativa, isto é, à medida que aumentava o teor total de ferro presente, aumentava a solubilização.

Manganês - Considerando o teor extraído dos fertilizantes solúveis (Figura 3a), observa-se que o DTPA tendeu a extrair mais, seguido do AC, CNA e

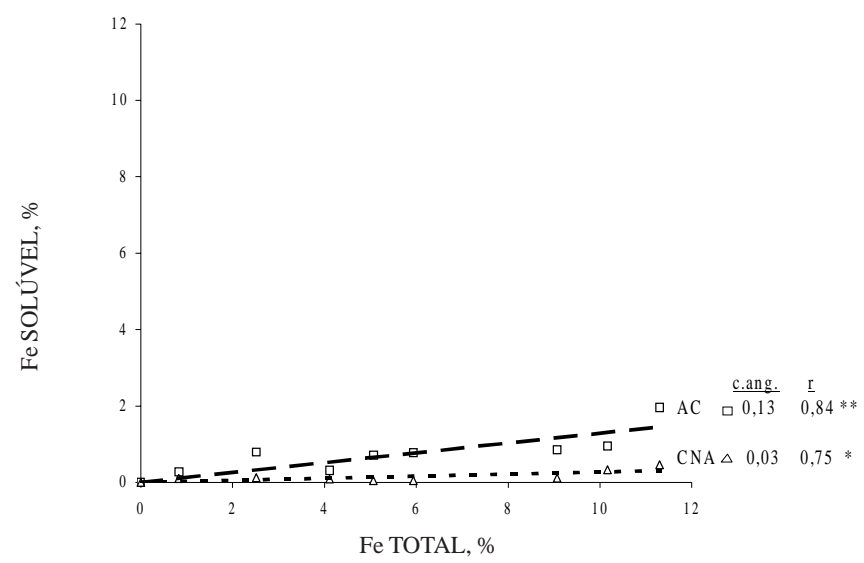

Figura 2. Solubilidade do ferro presente em fertilizantes insolúveis em água, nos diversos extratores utilizados, e respectivos coeficientes angulares das retas (c.ang.) e coeficientes de correlação (r). ** e* significativos a 5 e $1 \%$. água, com valores praticamente idênticos, e com o EDTA extraindo bem menos. Tais fatos podem ser comprovados pelos valores do coeficiente angular obtidos. A efetividade do AC, CNA e DTPA em solubilizar manganês é demonstrada em Ringbom (1963). A alta extração realizada pela água comprova que foram usadas fontes bastante solúveis no fornecimento de manganês aos fertilizantes. Os al tos e significativos coeficientes de correlação apresentados pel os extratores DTPA eágua indicam uma coerência na extração do manganês, isto é, aumentando o teor total, aumenta a extração. Para oAC, CNA eEDTA, a correlação não foi significativa. O pequeno número de amostras testadas deixam em dúvida a validade desse fato, para o AC e CNA. Porém, para o EDTA, a baixa eficácia na extração por si sójá desqualifica o extrator como eficiente na determinação de manganês disponível em fertilizantes, no pH e concentração testados.

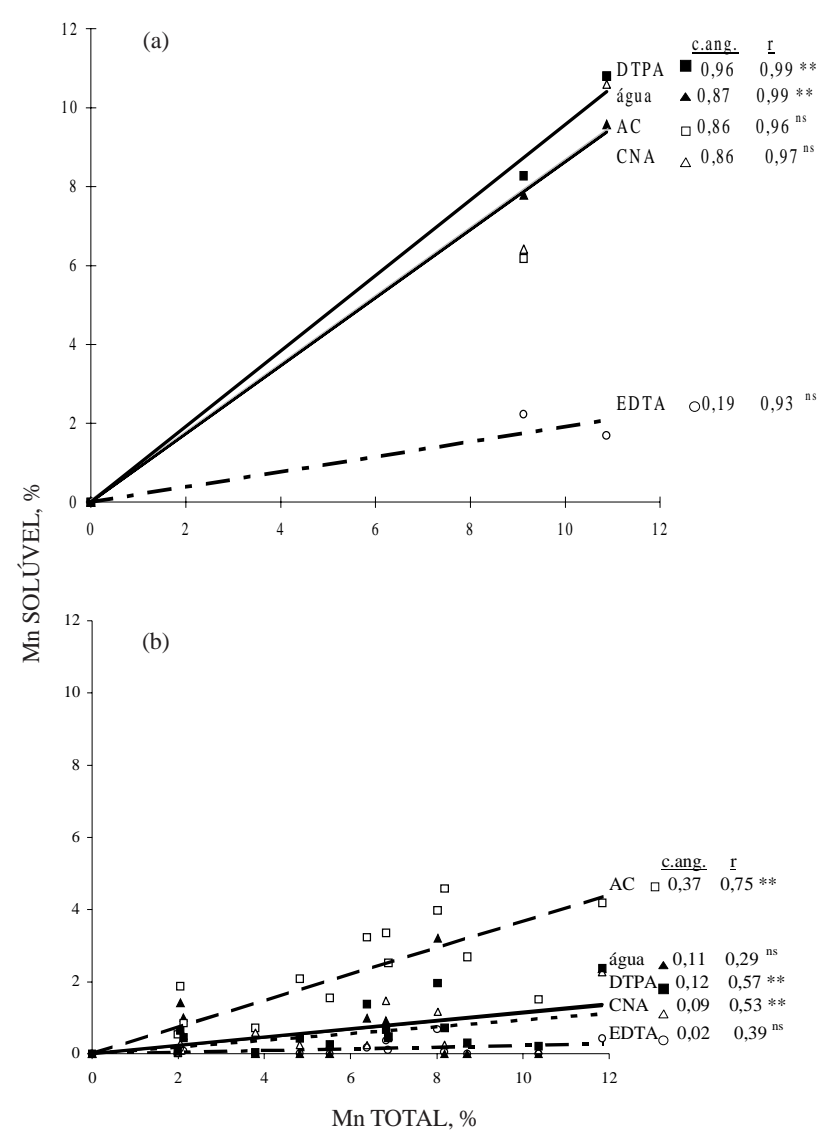

Figura 3. Solubilidade do manganês presente em ferti lizantes comerciais solúveis (a) e insolúveis em água (b), nos di versos extratores utilizados, e respectivos coeficientes angulares das retas (c.ang.) e coeficientes de correlação ( $r$ ). ** e ns significativos a $5 \%$ e não-significativo, respecitvamente. 
Na figura 3b, observa-se que o manganês foi pouco solubilizado nos fertilizantes tipo "fritas" por todos os extratores testados, fato evidenciado pelos baixos coeficientes angulares, o que indica utilização de fontes de baixa solubilidade. Houve tendência semelhante de extração por parte dos extratores água, CNA e DTPA, em média extraindo $11 \%$ do manganês total. Também os coeficientes de correlação para esses três extratores foram baixos e não-significativos, indicando extração não coerente das diferentes fontes. Essa éoutra evidência à adição de produtos não contemplados como fonte de manganês pela legislação. Com a maior extração realizada pelo $A C$ e com coeficiente de correlação também superior e significativo, fica novamente a suspeita se a acidez el evada do extrator (Alcarde \& Ponchio, 1979) não estaria favorecendo a liberação de manganês insolúvel à solução. A extração praticamente nula por parte do EDTA reforça a baixa eficiência desse extrator na solubilização do manganês dos fertilizantes.

Cobre - Para avaliar a solubilidade de cobre presente em fertilizantes solúveis, foi utilizada apenas uma amostra encontrada no mercado (Nitrex MS - 2), garantindo $1 \%$ do el emento. Observou-se que apresentou teor total de cobre ao redor de $91 \%$ do garantido. As extrações com água, CNA e DTPA foram semel hantes ( $85 \%$ do garantido) e próximas do teor total encontrado, ficando o AC um pouco abaixo (77\%). O EDTA foi o extrator que menos solubilizou cobre (63\%), como também ocorreu para todos os outros micronutrientes metálicos testados, praticamente desqualificando este extrator, no pH e na concentração utilizados. Esses dados dão uma visão geral de quefoi adicionado produto altamente solúvel na fabricação do fertilizante, fato evidenciado pela alta solubilidade em água. Porém, seria necessário o uso de mais fontes para comprovar esses fatos.

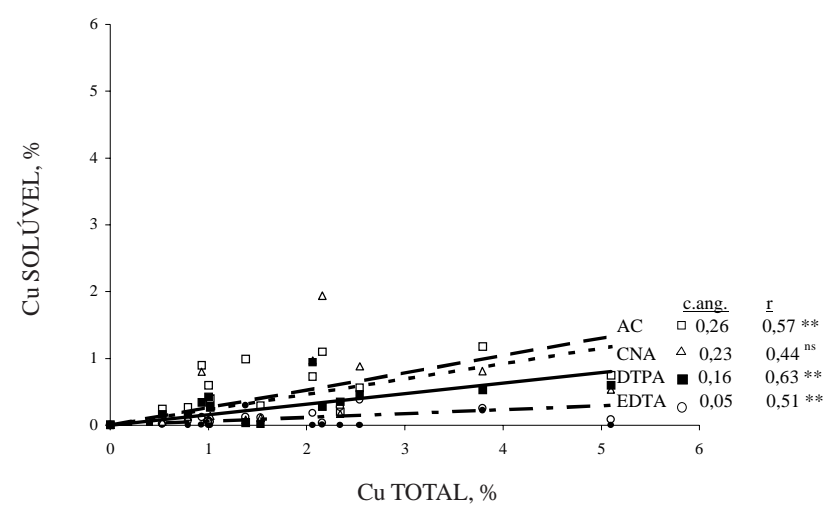

Figura 4. Solubilidade do cobre presente em fertilizantes insolúveis em água, nos diversos extratores utilizados, e respectivos coeficientes angulares das retas (c.ang.) e coeficientes de correlação ( $r$ ). ** e ns significativos a $5 \%$ e nãosignificativo, respecitvamente.
Na figura 4, são apresentadas as tendências de solubilização do cobre pelos diferentes extratores, dos fertilizantes de baixa solubilidade e com garantia do el emento. A primeira constatação éa sol ubilidade zero do cobre em água, indicando a utilização de fontes bastante insolúveis na fabricação desses fertilizantes, já que, como visto anteriormente, a água revela grande capacidade de solubilizar cobre em formas solúveis presentes. Entre os outros extratores, oAC, que foi um dos que menos extraiu o cobre da fonte solúvel, foi o que mais extraiu, seguido bem próximo pelo CNA, e mais abaixo pelo DTPA e peloEDTA. Os teores extraídos, porém, foram baixos, de acordo com os val ores dos coeficientes angulares apresentados. E sses val ores são mais uma indicação da utilização de fontes não consideradas pela legislação para o fornecimento de cobre.

Boro - Na figura 5a, observam-se as extrações de boro de todos os fertilizantes considerados solúveis. O extrator DTPA foi o que mais extraiu, fato evidenciado pelo maior coeficiente angular, seguido da água eEDTA, praticamenteiguais, emais abaixo pelo AC e pelo CNA. O valor do coeficiente angular da reta pode ser considerado, grosso modo, como a porcentagem de solubilização média de boro por parte do extrator considerado; por exemplo, o val or de 0,92 para oDTPA indica que houve extração de aproximadamente $92 \%$ do borototal pel o extrator. Levando em conta o nível de significância das correlações e considerando que, quanto mais significativas, mais coerentes as extrações, isto é, aumentando o teor total, aumenta o teor extraído, observa-se que o DTPA obteve coeficiente de correlação próximo de 1,0, altamente significativo a 1\%; água e EDTA tiveram significância a 5\%, enquanto para AC e CNA as correlações não foram significativas. O boro, pela legislação, é adicionado aos fertilizantes em formas de boratos de sódio e boratos de cálcio, considerados insolúveis em água, mas solubilizados por ácidos e, como ácido bórico, solúvel em água. Considerando que, teoricamente, todo o boro nesses fertilizantes teria de estar prontamente disponível, fica uma evidência de que o extrator DTPA foi o que mais eficientemente extraiu o boro disponível dos fertilizantes.

O comportamento dos extratores perante as fontes insolúveis em água (Figura $5 b$ ) mostrou que oDTPA foi o extrator mais eficiente, evidenciado pelo al to coeficiente angular. Em seguida, posicionaramse, pela ordem, CNA, AC, EDTA e água. A menor extração desse último extrator élógica, pela própria característica dos fertilizantes insolúveis em água. Os altos e significativos coeficientes de correlação apresentados por todos extratores mostram que todos estão extraindo coerentemente o boro solúvel de todas amostras, isto é, estão extraindo somente formas químicas semelhantes presentes nos diferentes fertilizantes. Isto provavelmente está indicando que foram usadas fontes com boro bastante solúvel na fabricação desses produtos. 
Levando em conta os dados da figura 5, em conjunto, pode-se chegar à conclusão de que o DTPA foi o extrator que mel hor caracterizou a solubilidade de boro nos fertilizantes.

Molibdênio - $O$ molibdênio éum micronutriente que, considerando a pequena quantidade requerida pelas plantas, é adicionado em quantidades totais muito baixas aos fertilizantes, conforme se observa no quadro 1. Com exceção das amostras 2 e 16, que garantem, respectivamente, 6 e 1,3\% do el emento, os demais fertilizantes garantem de 0,01 a $0,2 \%$, teores muito baixos que, com pequenas variações, ocasionam diferenças percentuais muito significativas de molibdênio. Somente por essa constatação, já se prevê uma dificuldade muito grande na avaliação da disponibilidade do el emento nos fertilizantes.

A caracterização da solubilidade do molibdênio pelos diferentes extratores é apresentada na figura $6 a$, para todos os fertilizantes, efigura $6 \mathrm{~b}$, para os fertilizantes com baixo teor do elemento. Pelas figuras, observa-segrande incoerência de resultados. Em cada caso, ocorreu uma tendência diferenciada de extração pelos extratores, por causa da grande diferença de teores apresentada pel os fertilizantes; a presença de mais fertilizantes em doses intermediárias favoreceria mel hor estudo. Também o estudo com produtos com doses muito baixas compromete a exatidão dos dados, como já. A boa solubilidade em água da maioria dos produtos com baixo teor de molibdênio leva à indicação de que o micronutrientefoi fornecido em formas solúveis aos fertilizantes. As amostras com teor el evado apresentaram baixa solubilidade em água, o que indica produtos mais insolúveis em sua composição; porém foram solubilizados pel os extratores químicos.

Disponibilidadedos micronutrientes para as plantas pelo método de Neubauer \& Schneider - No quadro 2, encontram-se as quantidades deboro, cobre, ferro, manganês e zinco acumuladas pelas plantas de arroz, após a realização do teste de Neubauer \& Schneider.

No quadro 3, são apresentados os coeficientes de correlação obtidos entrea quanti dade de boro, cobre, ferro, manganês e zinco acumulados pelas plantas dearroz eas quantidades fornecidas pel os fertilizantes, baseando-se no teor total e nos teores solúveis nos diferentes extratores. Para o el emento boro, observase que a correlação foi altamente significativa a 1\% para todos os extratores utilizados.

Isto demonstra ainda mais que todos extratores sol ubilizaram coerentemente o boro solúvel detodas amostras, isto é, estão extraindo somente formas químicas semelhantes presentes nos diferentes fertilizantes. Isto provavel mente está indicando que foram usadas, na fabricação desses produtos, fontes com boro passível de ser liberado às plantas. E o maior valor de correlação apresentado entre a quantidade acumulada e a fornecida baseando-se no teor total constitui indicativo de que a garantia de boro nos fertilizantes por esse parâmetro, como contemplado pela legislação, éválida. É interessante lembrar que, na fabricação de fertilizantes com boro, não existe um produto alternativo para o fornecimento do el emento: têm de ser usadas fontes reconhecidamente solúveis pela legislação, como ácido bórico ou ulexita, por exemplo.

As maiores emais significativas correl ações entre a quantidade acumulada de cobre e as fornecidas ocorreram quando foram utilizados os extratores AC e CNA; para os agentes quelantes DTPA e EDTA, assim como para a água, as correlações não foram significativas, comprovando a pouca efetividade desses extratores na aval iação da disponibilidade do cobre. Associando as pequenas quantidades de cobre solubilizadas pelos extratores (Figura 4) com a pequena recuperação do el emento pelas plantas, em
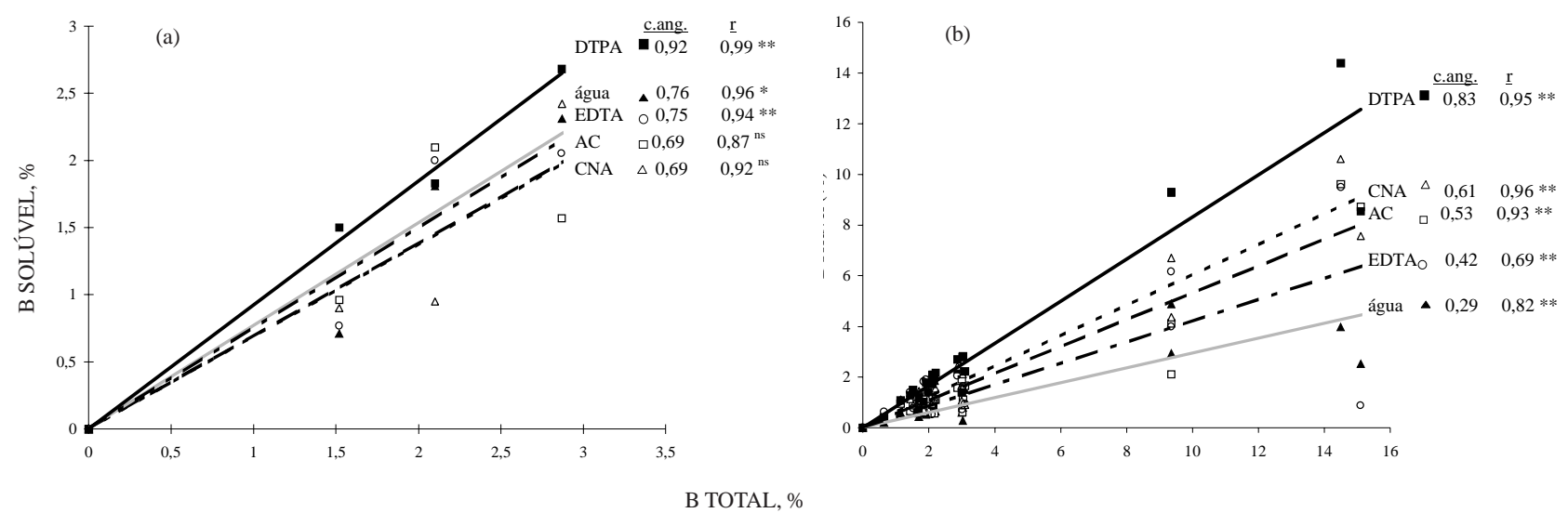

Figura 5. Solubilidade do boro presente em fertilizantes comerciais solúveis (a) e insolúveis em água (b), nos diversos extratores utilizados, e respectivos coeficientes angulares das retas (c.ang.) e coeficientes de correlação (r). ** e ns significativo a 5\% e não-significativo, respecitvamente. 

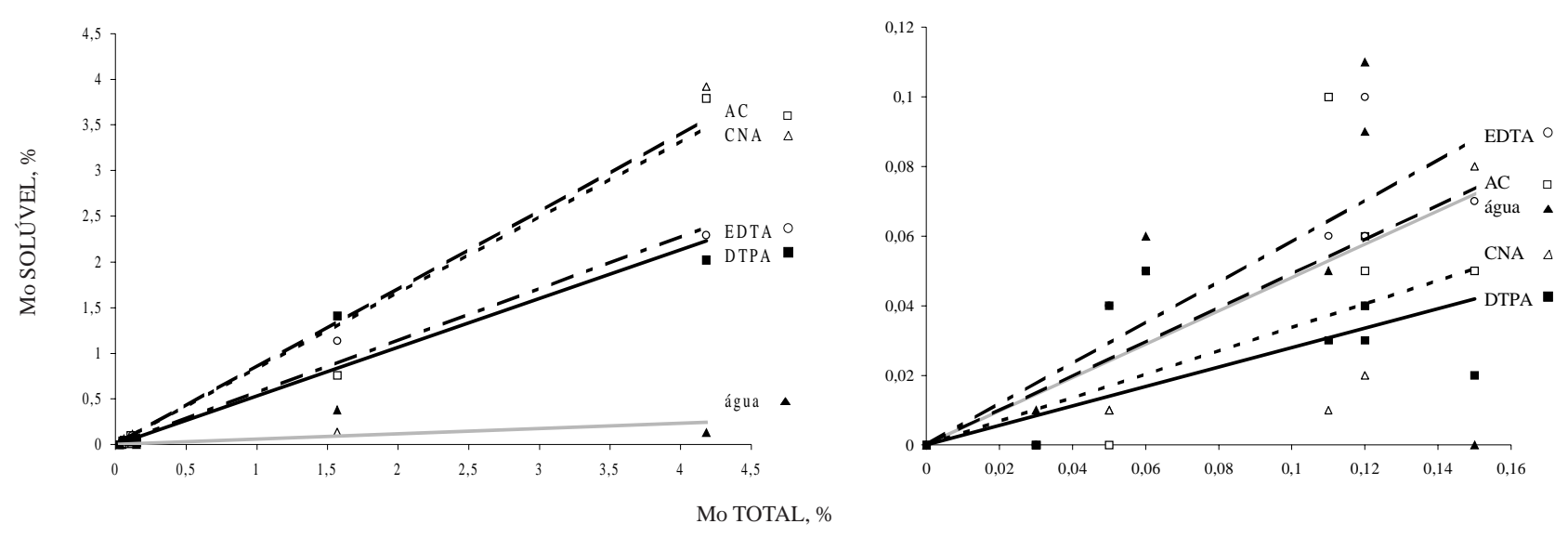

Figura 6. Solubilidade do molibdênio presente em fertilizantes comerciais, nos diferentes extratores, considerando todas as amostras (a) e somente nas amostras com baixo teor do elemento (b).

Quadro 2. Dose de cada micronutriente fornecido e teores acumulados por plantas de arroz, pelo método de Neubauer \& Schneider

\begin{tabular}{|c|c|c|c|c|c|c|c|c|c|c|c|}
\hline \multirow{2}{*}{ № } & \multirow{2}{*}{ Identificação } & \multicolumn{2}{|c|}{ B } & \multicolumn{2}{|c|}{ Cu } & \multicolumn{2}{|c|}{$\mathbf{F e}$} & \multicolumn{2}{|c|}{ Mn } & \multicolumn{2}{|c|}{$\mathbf{Z n}$} \\
\hline & & Dose & Planta & Dose & Planta & Dose & Planta & Dose & Planta & Dose & Planta \\
\hline & & & & & & $-\mu$ & & & & & - \\
\hline 1 & FTE BR-12 & 19,8 & 12,1 & 9,3 & 1,30 & 101,6 & 3,20 & 68,2 & 9,50 & 205,3 & 18,7 \\
\hline 2 & FTE Sementes & 10,5 & 10,9 & - & - & - & - & 37,9 & 3,40 & 207,7 & 30,1 \\
\hline 3 & FTE J CO 2M & 19,2 & 13,6 & 51,0 & 2,50 & 50,7 & 8,40 & 87,0 & 12,8 & 41,4 & 20,9 \\
\hline 4 & FTE Centro Oeste & 30,0 & 20,8 & 10,0 & 0,80 & - & - & 63,8 & 3,50 & 179,3 & 28,2 \\
\hline 5 & Nutricitro 224 & 22,0 & 11,3 & - & - & - & - & 48,2 & 4,70 & 224,8 & 93,0 \\
\hline 6 & Borogran - 10 & 93,6 & 33,4 & - & - & - & - & - & - & - & - \\
\hline 7 & Hidrozinc F rit 20 & - & - & - & - & - & - & - & - & 201,3 & 119,0 \\
\hline 8 & FTE Cerrrado S & 6,40 & 2,50 & 20,6 & 2,30 & - & - & 55,1 & 9,80 & 112,0 & 76,2 \\
\hline 9 & Zincogran 20 & - & - & - & - & - & - & - & - & 200,5 & 97,0 \\
\hline 10 & FTE BR - 18 & 30,3 & 14,4 & 25,4 & 3,80 & - & - & - & - & 179,2 & 85,0 \\
\hline 11 & FTE BR - 8 & 21,8 & 15,0 & 15,3 & 1,00 & 59,4 & 0,50 & 103,6 & 2,50 & 88,1 & 14,8 \\
\hline 12 & Zincoman & - & - & 37,9 & 3,60 & - & - & 118,3 & 22,0 & 82,6 & 61,3 \\
\hline 13 & Mib- 4 & 31,0 & 18,9 & - & - & - & - & - & - & 172,7 & 67,0 \\
\hline 14 & Mib- 3 & 14,4 & 3,80 & 5,30 & 0,70 & 25,1 & 5,30 & 20,5 & 6,30 & 77,8 & 12,0 \\
\hline 15 & Mib- 3 & 16,8 & 9,70 & 7,90 & 0,90 & 41,1 & 1,50 & 21,2 & 4,40 & 88,1 & 51,4 \\
\hline 16 & Mib-16A & 30,2 & 6,90 & - & - & - & - & - & - & 304,0 & 99,0 \\
\hline 17 & Mib - 28 & 21,3 & 11,0 & 13,8 & 2,50 & - & - & 80,2 & 19,2 & 145,6 & 89,4 \\
\hline 18 & Agrimax-12 & 17,0 & 12,9 & 10,2 & 0,40 & 90,6 & 1,50 & 19,9 & 1,50 & 86,8 & 12,0 \\
\hline 19 & Gran-o-zinc 20 & - & - & - & - & 113,0 & 8,50 & - & - & 181,1 & 48,4 \\
\hline 20 & Gran-o-bor 10 & 93,5 & 32,9 & - & - & - & - & - & - & - & - \\
\hline 21 & Agrimax CO 150 & 21,0 & 6,10 & 21,6 & 4,20 & - & - & 68,7 & 12,3 & 162,4 & 33,9 \\
\hline 22 & HGB 12 & 18,4 & 6,30 & 23,4 & 2,30 & - & - & 81,8 & 16,7 & 125,7 & 91,8 \\
\hline 23 & Plantzinco F IV & - & - & - & - & 8,30 & 0,50 & - & - & 542,5 & 103,0 \\
\hline 24 & Plantzinco F II & - & - & - & - & - & - & - & - & 200,8 & 102,8 \\
\hline 25 & Ulexita & 144,9 & 32,8 & - & - & - & - & - & - & - & - \\
\hline 26 & Boro Importado & 151,0 & 35,1 & - & - & - & - & - & - & - & - \\
\hline 27 & Nitrex MS - 2 & 15,2 & 8,90 & 9,10 & 3,00 & - & - & 91,2 & 20,0 & 179,3 & 64,6 \\
\hline 28 & Copas - 8 (café) & 28,7 & 2,90 & - & - & - & - & - & - & 78,3 & 80,7 \\
\hline 29 & Copas - 9 (citrus) & 21,0 & 4,20 & - & - & - & - & 108,7 & 67,4 & 188,0 & 122,8 \\
\hline 30 & Nutri Oxi-Zn "C" & - & - & - & - & - & - & - & - & 107,5 & 78,6 \\
\hline
\end{tabular}


Quadro 3. Coeficientes de correlação encontrados entre a quantidade de cada micronutriente acumulado pelas plantas de arroz, após realização do teste de Neubauer e Schneider, e as quantidades fornecidas pelos fertilizantes, baseando-se no teor total e nos teores solúveis nos diferentes extratores

\begin{tabular}{lccccc}
\hline \multicolumn{1}{c}{ Extração } & $\mathbf{B}$ & $\mathbf{C u}$ & $\mathbf{F e}$ & $\mathbf{M n}$ & $\mathbf{Z n}$ \\
\hline Teor total & $0,88^{* *}$ & $0,56^{* *}$ & $0,31^{\text {ns }}$ & $0,57^{* *}$ & $0,44^{* *}$ \\
Água & $0,56^{* *}$ & $0,32^{\text {ns }}$ & $0,20^{\text {ns }}$ & $0,83^{* *}$ & $0,41^{* *}$ \\
A.C. $2 \%$ & $0,75^{* *}$ & $0,64^{* *}$ & $0,63^{\text {ns }}$ & $0,93^{* *}$ & $0,51^{* *}$ \\
C.N.A. $(1+9)$ & $0,80^{* *}$ & $0,73^{* *}$ & $0,46^{\text {ns }}$ & $0,90^{* *}$ & $0,40^{*}$ \\
DTPA & $0,84^{* *}$ & $0,39^{\text {ns }}$ & $0,16^{\text {ns }}$ & $0,85^{* *}$ & $0,35^{\text {ns }}$ \\
EDTA & $0,61^{* *}$ & $0,49^{\text {ns }}$ & $0,05^{\text {ns }}$ & $0,69^{* *}$ & $0,26^{\text {ns }}$ \\
\hline
\end{tabular}

$*, * *$, ns significativo a 5 e $1 \%$ e não-significativo, respectivamente.

relação ao teor total (Quadro 2), conclui-se que a garantia de cobre pelo teor total não foi um bom parâmetro: os extratores AC e CNA mostraram-se mais efetivos.

As baixíssimas extrações deferro pelos extratores (Figura 2), associadas à recuperação do elemento pelas plantas de arroz (Quadro 2), provavel mente acabaram refletindo na não-significância de todas as correlações apresentadas entre as quantidades acumuladas e as fornecidas. Nenhum extrator na solubilização do ferro mostrou-se realmente indicativo do disponível às plantas. Uma conclusão geral foi de que oteor total de ferroéum parâmetro inadequado para definir disponibilidade do elemento.

Para o manganês, observa-se (Quadro 3), que o teor total apresentou a menor correlação com o acumulado pelas plantas; novamente, esse parâmetro mostrou-se inadequado para caracterizar a disponibilidade para as plantas. Para os demais extratores, as correlações foram significativas, indicando que extraíram coerentemente as mesmas formas químicas presentes. O AC é o extrator que parece estar indi cando mel hor a solubilização do manganês para as plantas, seguido pelo CNA e pelo DTPA.

O extrator que melhor caracterizou a disponibilidade de zinco foi o AC, com correlação significativa a $1 \%$. Todavia, os valores dessas correlações foram bem baixos, quando comparados com os das correlações encontradas para os outros micronutrientes estudados. I sto pode ser um reflexo das altas doses dezinco fornecidas pel os fertilizantes.

Observou-se coerência entre o boro absorvido pelas plantas e o extraído dos fertilizantes pelos extratores. O mesmo ocorreu para os micronutrientes metálicos. Porém, esses resultados não são definitivos. Uma concordância geral para cobre, ferro, manganês ezinco foi que o teor total realmente não está caracterizando a disponibilidade desses micronutrientes nos fertilizantes. Recomenda-se estudo mais aprofundado com esses extratores mais promissores e com outros.

\section{CONCLUSÕES}

1. Os fertilizantes tipo "fritas" apresentaram baixa solubilidade dos micronutrientes catiônicos (cobre, ferro, manganês e zinco) em todos os extratores utilizados.

2. O ácido cítrico a $2 \%$ mostrou-se promissor na caracterização da disponibilidade de cobre, manganês e zinco para as plantas.

3. O boro teve boa solubilidade, tanto nos fertilizantes solúveis como nos insolúveis em água. A garantia pel o teor total mostrou-se bom indicativo da disponibilidade do elemento.

4. Para o molibdênio, produtos mais solúveis foram utilizados nos fertilizantes com baixo teor do elemento, enquanto os com teor mais elevado tenderam a uma menor solubilidade em água, mas solúveis nos extratores, indicando disponibilidade.

5. A garantia dos mi cronutrientes catiônicos pelo teor total, conforme exige a legislação, não indicou a real disponibilidade dos micronutrientes nos fertilizantes. Recomenda-se a definição de extratores para esse fim.

\section{LITE RATURA CITADA}

ALCARDE, J.C. \& PONCHIO, C.O. A ação solubilizante das soluções de citrato de amônio e de ácido cítrico sobre fertilizantes fosfatados. R. Bras. Ci. Solo, 3:173-178, 1979.

ALCARDE, J.C. \& RODELLA, A.A.. Caracterização de fertilizantes simples contendo zinco. Sci. Agríc., 50:121-126, 1993.

BRASIL. Ministério da Agricultura. Inspeção e fiscalização da produção e do comércio de fertilizantes, corretivos, inoculantes, estimulantes e biofertilizantes destinados à agricultura - Legislação e Fiscalização. Brasília, Secretaria Nacional de Defesa Agropecuária, Divisão de Corretivos e Fertilizantes, 1982. 88p.

BRASIL. Ministério da Agricultura. Análises de corretivos, fertilizantes e inoculantes Métodos oficiais. Brasília, Secretaria Nacional de Defesa Agropecuária, Laboratório Nacional de Referência Vegetal (LANARV), 1983. 104p.

CATANI, R.A. \& BERGAMIN FILHO, H. Sobre uma modificação no método de Neubauer. An. ESALQ, Piracicaba, 18:287299, 1961

HOAGLAND, D.R. \& ARNON, D.I. The water culture methods of growing plants without soil. Berkeley: University of California., 1950. p?.

J APÃO. National Institute of Agricultura Sciences. Official methods of analysis of fertilizers. Yatabe-Machi, 1982. 130p. 
KANE, P.F. Fertilizers. In: CUNNIFF, P., ed. Official Methods of Analysis, 16 ed. Arlington: AOAC International, 1995. p.139.

LINDSAY, W.L. \& NORVELL, W.A. Devel opment of a DTPA soil test for zinc, iron, manganese, and copper. Soil Sci. Soc. Am. J ., 42:421-428, 1978.
MALAVOLTA, E.; VITTI, G.C. \& OLIVEIRA, S.A. Avaliação do estado nutricional das plantas: princípios e aplicações. Piracicaba: Potafós, 1989. 201p.

RINGBOM, A. Complexation in analytical chemistry. New York, Interscience Publishers, 1963. 395p. 